\title{
Analysis of the effect of water steam concentration on water drop cooling process efficiency in conditions of water cooling towers of thermal power plants
}

\author{
Sergei Shevelev ${ }^{1, *}$ \\ ${ }^{1}$ National Research Tomsk Polytechnic University, 634050 Tomsk, Russia
}

\begin{abstract}
Numerical investigation of transient distribution of temperature in water drops cooled in cool blast in conditions typical for high capacity evaporative water cooling towers has been done. Water drops cooling through thermal conductivity and water evaporation has been taken into consideration. It has been proved that the analysis of temperature distribution along the radius of water drop increases reliability of evaluation results of average temperature of water drops when they are cooled. Effect of water steam concentration in steam-gas mixture layer surrounding a water drop on water cooling towers efficiency has been evaluated.
\end{abstract}

\section{Introduction}

Water cooling towers are an important part of water treatment system at thermal power plants (TPP) $[1,2]$. However, process cycle characteristics of recycled water evaporative cooling are selected experimentally and mainly with the help of integral process characteristics (temperature of large amounts of water after passing through water cooling towers) until recently. It is not possible to experimentally determine the temperature of water drops moving in comparatively cold (in comparison with recycled water) and dry air flow. At the same time the results of theoretical $[3,4]$ and experimental $[5,6]$ researches of water drops movement processes through gas flow have been known. The authors [3-6] have proved that temperature field of water drops when heated is not homogeneous (under certain conditions water drop temperature gradient is $20-30 \mathrm{~K}$ ). The analysis of water drops cooling processes during their movement through the cold air of water cooling towers is of interest. Moreover [4], water evaporation intensity is known to be dependent on its steam concentration near evaporation boundary (air humidity). Water cooling towers of TPP operate in conditions of atmospheric air intake for recycled water cooling without dehydration of the so called refrigerant. Therefore, analysis of air humidity effect on water drops cooling efficiency in operating paths of water cooling towers has acquired practical importance.

\footnotetext{
* Corresponding author: wevelev@tpu.ru
} 
The purpose of the paper is mathematical simulation of temperature fields of single water drops under water steam concentration variation in cold air.

\section{Research objective}

A spherical water drop is slow-speed under the gravity of approach cold air flow which temperature is significantly less than the initial temperature of water. Water drop cooling is due to convective heat transfer and evaporation heat absorption on the surface of the water drop. Water steam formed as a result of water evaporation is blown into near-wall region and mixed with air, and increases its humidity. The formed steam-gas mixture surrounds a drop. The dimensions of the drop decrease over time due to the removal of the part of the mixture with water steam.

It was assumed that the diameter of water drops is significantly smaller than the distance between them. Therefore, it is supposed that heat removal from the water drop has no significant effect on the temperature of the surrounding steam-gas mixture. Heat transfer coefficient was determined for conditions of flow around the sphere by a flow with low velocities due to low velocity of water drops.

Thermophysical characteristics of components of 'drop-air-water steam' system are taken as depending on temperature and pressure (for water they were determined according to the data from [7], for air according to figures provided by [8]).

The scheme of problem solution region is presented in Fig. 1.

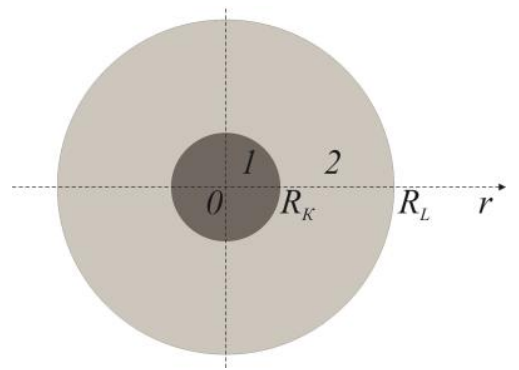

Fig. 1. Scheme of problem solution region. 1 - water drop, 2 - humid air.

The problem of heat and mass transfer set above is described with the help of the system of differential equations in partial differential coefficients written in spherical system of coordinates.

$$
\rho c \frac{\partial T}{\partial t}=\lambda\left(\frac{\partial^{2} T}{\partial r^{2}}+\frac{2}{r} \frac{\partial T}{\partial r}\right), 0<r<R_{K}
$$

Here: $T, K$ - temperature; $\rho, \mathrm{kg} / \mathrm{m}^{3}$ - density, $c, \mathrm{~J} /(\mathrm{kg} \cdot \mathrm{K})$ - heating capacity; $\lambda$, $\mathrm{W} /(\mathrm{m} \cdot \mathrm{K})$ - thermal conductivity, $C_{w s}$ - water steam concentration, $\mathrm{D}, \mathrm{m}^{2} / \mathrm{s}-$ water steam diffusion coefficient.

Boundary data:

$$
\begin{gathered}
r=0: \frac{\partial T}{\partial r}=0 \\
r=R_{K}:-\lambda \frac{\partial T}{\partial r}=\alpha\left(T_{\Gamma}-T_{B}\right)+Q W
\end{gathered}
$$




$$
\begin{gathered}
r=R_{K}:-D \frac{\partial C_{w s .}}{\partial r}=\frac{W}{\rho_{2}} \\
r=R_{L}: \frac{\partial C_{w s}}{\partial r}=0
\end{gathered}
$$

Here, $Q, J / \mathrm{kg}$ - heat of phase change; $W, \mathrm{~kg} /\left(\mathrm{m}^{2} \cdot s\right)$ - mass rate of vaporization, defined with mathematical expression of Hertz-Knudsen law, in accordance with [8].

The system of equations (1) - (2) presented above, with the initial and boundary data (3) - (8) was solved with the finite difference method using a tacit finite-difference scheme. The method of catching the front into a special grid node was used to take into account the movable boundary of the phase transfer. Non-linier problem of heat and mass transfer (1) (8) was solved with the iteration method similar to [9]. The solution of differential rates of differential equations was carried out with the sweep method.

\section{Results and discussion}

Numerical modelling was carried out at rather typical initial data values: $T_{0}=323 \mathrm{~K}$, $T_{B}=288 \mathrm{~K}, D=2.16 \cdot 10^{-5} \mathrm{~m}^{2} / \mathrm{s}$.

Fig. 2 shows temperature distribution along the radius of the water drop over time. The radius of the water drop at the initial time is $5 \mathrm{~mm}$.

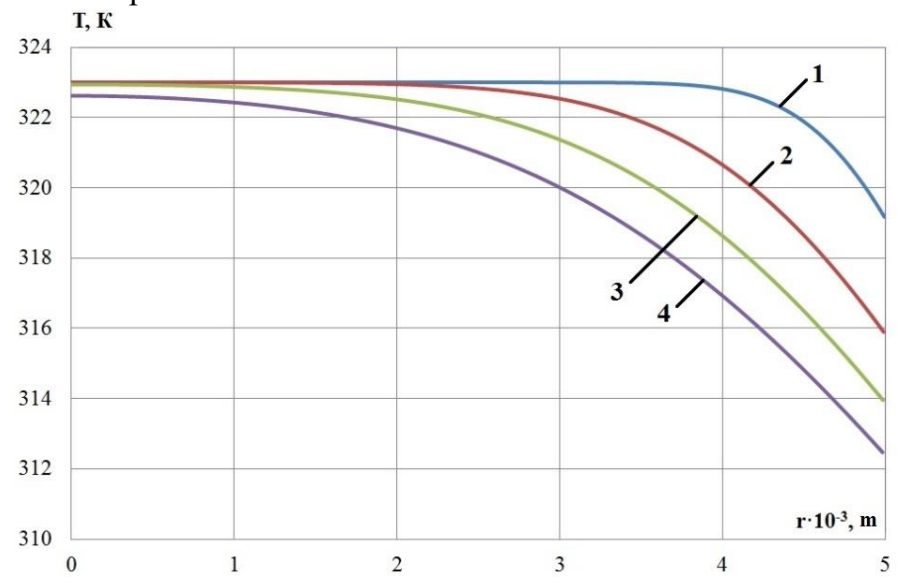

Fig. 2. Temperature distribution along the radius of the water drop $\left(R_{K}=5 \mathrm{~mm}, C_{0}=0.01\right)$ over time: 1 $-\mathrm{t}=1 \mathrm{~s} ; 2-\mathrm{t}=4 \mathrm{~s} ; 3-\mathrm{t}=7 \mathrm{~s} ; 4-\mathrm{t}=10 \mathrm{~s}$.

Based on the dependency analysis presented in Fig. 2, we can con-clude about the significant temperature difference along the radius of the water drop: in one second the temperature of the surface of the water drop is less than the temperature of its center by 3.8 $\mathrm{K}$, and in ten seconds by $10.2 \mathrm{~K}$. Herewith, the average temperature of the water drop is 321.6 and $316.4 \mathrm{~K}$ respectively. Thus, recycled water temperature evaluation at the outlet of the water cooling tower by water drop surface temperature may cause incorrect results. Therefore, in mathematical simulation of water drops cooling in cold air flow under conditions typical for modern water cooling towers, temperature changes along the radius of the water drop must be taken into account.

Fig. 3 shows temperature distribution along the radius of the water drop over time for different water steam concentration values. 


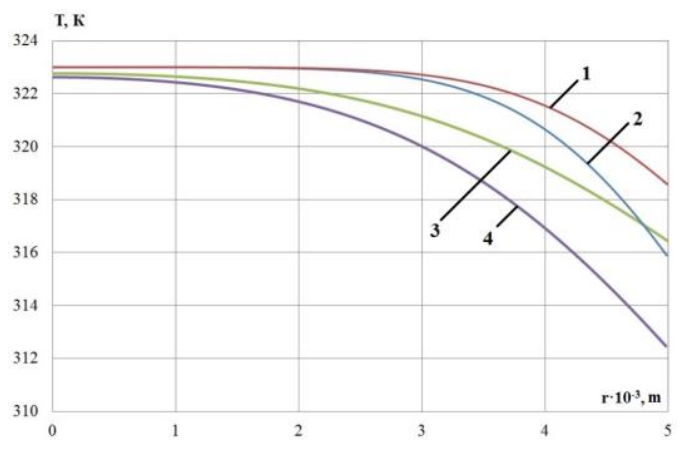

Fig. 3. Temperature distribution along the radius of the water drop over time for two water steam concentration values $\left(R_{K}=5 \mathrm{~mm}\right): C_{0}=0.05(1-\mathrm{t}=1 \mathrm{~s} ; 3-\mathrm{t}=10 \mathrm{~s}) ; C_{0}=0.01(2-\mathrm{t}=4 \mathrm{~s} ; 4-\mathrm{t}=10 \mathrm{~s})$.

According to the result of the analysis of dependencies presented in Fig. 3 we can conclude about the significant effect of initial water steam concentration on the temperature distribution along the radius of the water drop. So increase of $\mathrm{C} 0$ from 0.01 to 0.05 after four seconds of flight causes average integrated temperature increase of water drops by 1.2 $\mathrm{K}$ and by $2.4 \mathrm{~K}$ after ten seconds accordingly. Consequently, when creating a mathematical model designed for recycled water cooling efficiency evaluation in a water cooling tower both the value of water steam concentration and the temperature and air velocity must be considered.

\section{Conclusion}

As a result of the theoretical research the necessity and reasonability of the account of the effect of water steam concentration on temperature of drops at calculation of water cooling in technical water supply systems have been shown. The established results and common factors can be used for development of mathematical models of heat and mass transfer processes in the movement of water drops heated to high temperatures when they are cooled in water cooling towers.

\section{References}

1. S. R. Alavi, M. Rahmati, Energy Convers. Manage 122, 504 (2016)

2. L. D. Berman, Evaporative cooling of circulating water (Pergamon, London, 1961)

3. G. V. Kuznetsov, P. A. Stizhak, J. Eng. Phys. Thermophys. 87, 1 (2014)

4. G. V. Kuznetsov, P. A. Strizhak, High Temp. 52, 4 (2014)

5. R. S. Volkov, G. V. Kuznetsov, P. A. Stizhak, Tech. Phys. 59, 7 (2014)

6. G. V. Kuznetsov, P. A. Stizhak, Tech. Phys. Lett. 40, 6 (2014).

7. Y. Sun, Z. Guan, K. Hooman, Renew. Sust. Energ. Rev. 79, 618 (2017)

8. Revised Release on the IAPWS Industrial Formulation 1997 for the Thermodynamic Properties of Water and Steam. The International Association for the Properties of Water and Steam www.iapws.org (Lucerne, Switzerland, 1997)

9. A. A. Zukauskas, High-performance single-phase heat exchangers (Hemisphere Publishing Corporation, London, 1989)

10. V. L. Strakhov, A. N. Garashchenko, G. V. Kuznetsov, V. P. Rudzinskii, Combust. Explos. 37, 2 (2001) 